\title{
Aplicação da prática colaborativa no desenvolvimento de um jogo para o ensino da programação
}

\author{
Mauro Marcelo Mattos ${ }^{1}$, Luciana Pereira de Araújo ${ }^{1}$, Fabrícia Durieux Zucco ${ }^{2}$ \\ Nelson Hein ${ }^{3}$, Karina Zendron da Cunha ${ }^{4}$, Gabriel Castellani de Oliveira ${ }^{1}$ \\ Leonardo Rossi Bordone ${ }^{1}$, Nathan Kruger ${ }^{1}$, Lucas Eduardo Schlögl ${ }^{1}$ \\ Adriane Tomé ${ }^{4}$, Pedro Lima Bursoni ${ }^{2}$ \\ ${ }^{1}$ Laboratório de Desenvolvimento e Transferência de Tecnologias (LDTT) \\ Departamento de Sistemas e Computação \\ Universidade Regional de Blumenal (FURB) - Blumenau, SC - Brazil \\ ${ }^{2}$ Departamento de Comunicação \\ Universidade Regional de Blumenal (FURB) - Blumenau, SC - Brazil \\ ${ }^{3}$ Departamento de Matemática \\ Universidade Regional de Blumenal (FURB) - Blumenau, SC - Brazil \\ ${ }^{4}$ Departamento de Letras \\ Universidade Regional de Blumenal (FURB) - Blumenau, SC - Brazil
}

\begin{abstract}
Resumo. Este artigo é parte de um projeto de extensão que tem por objetivo ensinar crianças a programar através de joguinhos. $O$ artigo apresenta a fase de concepção do jogo, o qual foi realizada por uma equipe interdisciplinar de computação, comunicação e letras. Para a concepção foram utilizadas técnicas de design colaborativo e foi aplicado o método CARD para a definição das regras do jogo. Para a produção, utilizou-se da abordagem de processos de negócio de forma colaborativa, na qual foi definido um fluxo de atividades para cada parte da equipe. Este artigo apresenta o desenvolvimento e discute a aplicabilidade dos métodos para a concepção de um produto.
\end{abstract}

\section{Introdução}

O termo "Pensamento Computacional" (WING, 2006) traz uma nova abordagem para a área da Ciência Cognitiva e da Ciência da Computação, pois parte da premissa de que a inserção dos conceitos da Ciência da Computação na educação básica desenvolve uma habilidade de abstração diferente, a qual ajuda as crianças na resolução de problemas em todas as áreas da vida. Dessa forma, o Pensamento Computacional é uma habilidade para todos, e não apenas para futuros cientistas da computação.

Conforme Nunes (2011), o raciocínio computacional é intuitivo no ser humano e se manifesta já na idade infantil. Portanto, a criança naturalmente raciocina de forma computacional. Por exemplo, uma criança tem a capacidade de realizar várias atividades (algoritmos) em paralelo (simultaneamente), mantendo controle sobre elas. Entretanto, tal capacidade não é explorada adequadamente na educação básica. Como consequência, o raciocínio intuitivo (e computacional) se perde ao longo do desenvolvimento do indivíduo, 
a tal ponto que, em geral, um adolescente tem mais dificuldades de resolver problemas de maneira intuitiva e, consequentemente, de maneira computacional, do que uma criança.

A Extensão Universitária caracteriza-se com um processo interdisciplinar, educativo, cultural, científico e político que promove a interação transformadora entre Universidade e outros setores da sociedade. Sabe-se também que a relação dialógica entre universidade e sociedade promove a interação entre teoria e prática e potencializa a articulação entre os saberes sistematizados, acadêmicos e populares.

O projeto Furbot foi concebido como ferramenta de apoio ao ensino de conceitos de programação e vem sendo utilizado desde 2008 na disciplina de introdução a programação do primeiro semestre dos cursos de Sistemas de Informação e Ciência da Computação. Como a ferramenta atual foi desenvolvida por profissionais da computação que atuam no ensino superior, a ferramenta está voltada para este pública alvo. Assim, se por um lado a experiência de oito anos de alguns dos extensionistas com o uso da ferramenta endossa a iniciativa de leva-la para estudantes do Ensino Fundamental, os quais têm menor contato com disciplinas que fomentam o raciocínio lógico e o pensamento computacional (WING, 2006), por outro lado, coloca um desafio que justifica a composição da equipe interdisciplinar para esse projeto, já que é preciso despertar o interesse dos alunos pelos saberes associados aos conteúdos que serão desenvolvidos, seja por meio de um layout mais atrativo para a ferramenta, seja pela proposta pedagógica envolvida na elaboração das oficinas.

Como o layout da ferramenta é bastante simples, o desafio da equipe interdisciplinar do projeto é adequar o ambiente do Furbot para a realidade da Educação Básica e possibilitar o desenvolvimento de conteúdos adequados à idade, à maturidade e às características dos recursos humanos envolvidos (qualificação tecnológica dos professores da escola), bem como da infraestrutura de TI disponível aos alunos.

Como primeiro ponto de atividade, decidiu-se construir um tabuleiro físico baseado na ferramenta Furbot para que as crianças entre 9 e 10 anos possam ter os primeiros conceitos de programação. Para a construção deste, utilizou-se das práticas colaborativas em um ambiente interdisciplinar.

Dentro desse contexto, o presente artigo está dividido da seguinte forma. A seção 2 apresenta alguns trabalhos relacionados ao jogo a ser desenvolvido. A seção 3 discorre sobre as práticas colaborativas no desenvolvimento de um produto. A seção 4 discute o desenvolvimento do tabuleiro através de um estudo de caso no qual foi aplicada a metodologia das práticas colaborativas. Por fim, a seção 5 apresenta a conclusão e os trabalhos futuros.

\section{Trabalhos Relacionados}

Foi realizada uma pesquisa com relação aos jogos de tabuleiro existentes no mercado que são voltados para o ensino da programação. Com base nos resultados encontrados, são apresentados três jogos de tabuleiro que auxiliam o aprendizado da programação, sendo C-Jump [Kholodov 2016], Robot Turtles [Lazowska and Etzioni 2014] e Robot Wars [Akuthota 2016].

O C-Jump [Kholodov 2016] tem por objetivo ensinar crianças a aprender conceitos das linguagens de programação $\mathrm{C}, \mathrm{C}++$ e Java. $\mathrm{O}$ jogo ocorre num tabuleiro com 
cenário de esquiadores (Figura 1), no qual o jogador que passar todos os seus esquiadores pela linha de chegada vence o jogo. Para alcançar a linha de chegada, o jogador deve seguir os passos do tabuleiro que são sequências de comandos de programação, como switch, if e else. Além dos comandos de programação, o jogo treina as habilidades matemáticas de soma, subtração, divisão e multiplicação. Os comandos de programação e cálculos devem ser executados em uma sequência lógica para que o jogador atinja seu objetivo final, sendo assim, o jogo auxilia no desenvolvimento da compreensão de um programa de computador, formado por sequências de passos lógicos.
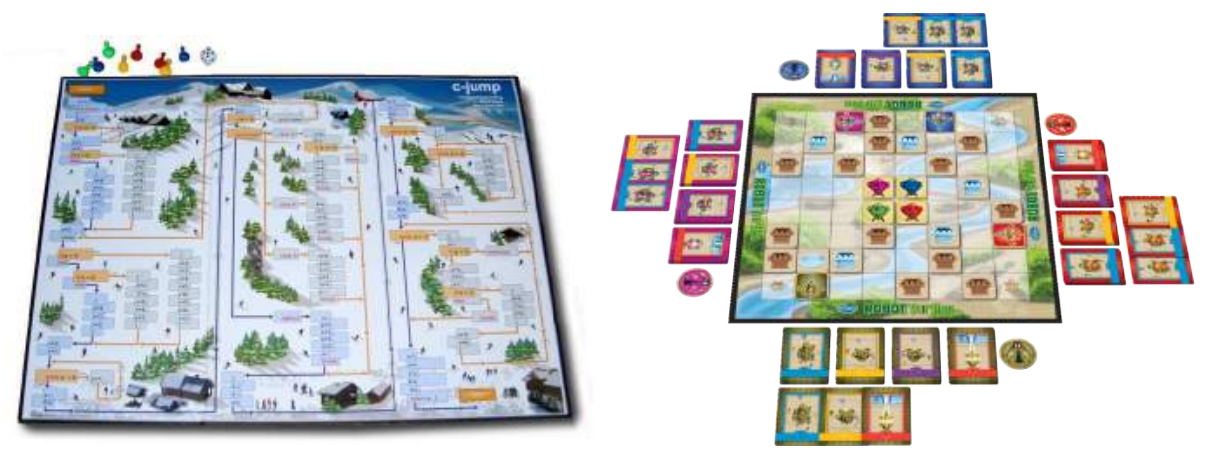

Figure 1. Tabuleiro c-jump (esquerda) e Robot Turtles (direita)

[Kholodov 2016]; [Lazowska and Etzioni 2014]

O jogo Robot Turtles [Lazowska and Etzioni 2014] é um jogo voltado para crianças entre 3 e 8 anos que ensina os fundamentos da programação. Os personagens do jogo são tartarugas e o cenário do tabuleiro possui algumas variações, sendo a mais comum uma paisagem de um lago. Cada jogador é responsável por uma tartaruga (representada através de uma carta) e precisa fazê-la chegar a um objetivo que varia conforme o enunciado da vez. Em alguns cenários, são colocados obstáculos pelo caminho de modo a bloquear algumas passagens, como apresentado na Figura 1. Para que a tartaruga atinja o objetivo ela deve utilizar outras cartas que contêm direções como virar e andar. O jogo ensina a criança a ter um pensamento lógico e sequencial de modo que consiga atingir o objetivo colocando as cartas no cenário.

Por fim, o jogo Robot Wars é um jogo de estratégia voltado a crianças e adultos, possuindo vários níveis que garantem o aprendizado progressivo. Cada jogador é responsável por um robô e recebe cartas que contém comandos de programação em Java. Há vários níveis de cartas sendo: $i$ iniciante, comandos para o aprendizado de passos sequenciais; $i i$ intermediário, formado por comandos condicionais e de repetição; e avançado, formado por chamada de métodos. O objetivo do participante é chegar ao ponto central do tabuleiro e durante o caminho do mapa pode "matar" os robôs adversários, sendo que devem retornar a casa inicial. Para andar pelo tabuleiro, o jogador na sua vez retira uma carta do monte (Figura 2), que contém uma instrução de movimentação (direita, esquerda, frente, trás) e, se conseguir realizar o movimento, tem direito a uma carta recurso. A carta recurso (Figura 2) contém um código-fonte mais elaborado com comandos condicionais, repetição ou função e podem ser utilizadas quando o jogador achar necessário. São através das cartas de recurso que o jogador aprende os comandos da programação. 

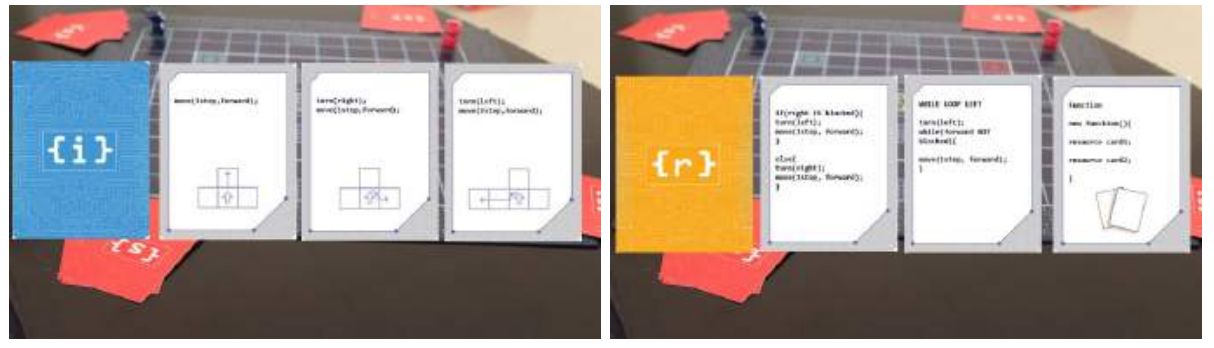

Figure 2. Carta de comando (esquerda) e Carta recurso (direita)

[Akuthota 2016]

\section{Práticas Colaborativas no Desenvolvimento de um Produto}

Através da atuação em grupo é possível promover a integração dos conhecimentos e capacidades de cada um, a partir dos pontos de vistas diferenciados e habilidades complementares [Fuks et al. 2002].

De acordo com [Fuks et al. 2002], a atuação em grupo tende a promover a integração de capacidades e de conhecimentos e, ainda, a interação entre pessoas com pontos de vista e habilidades complementares. Por meio da prática colaborativa, as pessoas podem obter feedback e identificar antecipadamente falhas e inconsistências, criar alternativas para a resolução dos problemas, selecionar as soluções viáveis e tomar decisões.

Desde a década de 90, o Modelo 3C de Colaboração tem sido aplicado para diferentes finalidades, tais como guiar a especificação de uma nova ferramenta ou produto [Pereira and Soares 2007] ou analisar o suporte computacional de uma já existente [Fuks et al. 2002]. Para o desenvolvimento de um produto, há um conjunto de passos a serem realizados para obtenção do resultado. Esses processo, se realizado de forma conjunta pela organização, tende a ser finalizado com sucesso mais precisamente. De acordo com [Santoro et al. 2012], um fator a ser levado em conta durante o processo do negócio é a colaboração, pois através dela é possível o compartilhamento do conhecimento afim de obter o sucesso da solução.

Durante a realização de um processo de forma colaborativa é importante que cada participante desempenhe uma responsabilidade sobre a execução de uma determinada tarefa [Santoro et al. 2012], sendo de acordo com sua habilidade [Fuks et al. 2002]. Esses participantes devem trocar informações ou elaborar artefatos de forma cooperada, buscando a solução para o negócio. Para que o processo do desenvolvimento de um novo negócio ocorra corretamente é necessário estabelecer regras, ordens e condições de execução, sendo que os elementos que compõem o processo são: objetivo, evento, atividade, ator/agente, entrada, saída e regra [Santoro et al. 2012].

De acordo com a Figura 3, definido por Santoro [Santoro et al. 2012], tem-se um modelo de como executar de forma prática a colaboração em um processo de negócio. Conforme pode-se observar, é necessário planejar como se dará a comunicação durante a execução da atividade, como será realizado o trabalho em grupo e quem serão os coordenadores de cada processo, como será realizada a integração dos produtos gerados individualmente e qual é a percepção social em relação a este planejamento inicial. Após a etapa do planejamento, há o processo do desenvolvimento do negócio, identificado pela etapa 
de percepção. Nessa etapa é necessário distribuir as informações entre os envolvidos, os coordenadores devem acompanhar o andamento das atividades, os membros devem cooperar entre si compartilhando os conhecimentos produzidos, sendo assim que todos os envolvidos devem ter a percepção do processo. Por fim, após a conclusão do processo é importante que haja um momento reflexivo. Nessa etapa deve-se realizar uma reunião de encerramento, afim de avaliar o produto final e compartilhar o conhecimento tácito gerado com o desenvolvimento do produto. Ainda nessa etapa é importante que os membros tenham a percepção da colaboração durante o processo do negócio.

\begin{tabular}{|c|c|c|c|c|}
\hline & Comunicação & Coordenaçäo & Cooperaçäo & Percepçäo \\
\hline Planejado & $\begin{array}{l}\text { Planejamento da } \\
\text { comunicaçằ }\end{array}$ & $\begin{array}{l}\text { Planejamento de } \\
\text { trabalho em grupo }\end{array}$ & $\begin{array}{l}\text { Integraçăo de } \\
\text { produt os indluiduais }\end{array}$ & $\begin{array}{l}\text { Percepçằ } \\
\text { social }\end{array}$ \\
\hline Perceptivo & $\begin{array}{l}\text { Distribuiçăo das } \\
\text { informaçôes }\end{array}$ & Acompanhamento & $\begin{array}{l}\text { Compartilhamento de } \\
\text { conhecimento } \\
\text { explicito }\end{array}$ & $\begin{array}{c}\text { Percepçăo de } \\
\text { processo }\end{array}$ \\
\hline Reflexivo & $\begin{array}{l}\text { Reuniăo de } \\
\text { encerramento }\end{array}$ & Avaliaçăo & $\begin{array}{l}\text { Compartilhamento de } \\
\text { conhecimento tácito }\end{array}$ & $\begin{array}{l}\text { Percep çào da } \\
\text { colaboraçăo }\end{array}$ \\
\hline
\end{tabular}

Figure 3. Práticas para um projeto de colaboração no processo do negócio

[Santoro et al. 2012]

\section{Desenvolvimento do Processo}

Com o objetivo de construir um projeto que atraia a atenção das crianças para o aprendizado da lógica, viu-se a necessidade de uma equipe interdisciplinar. Dessa forma, a equipe composta por membros dos cursos de Ciência da Computação, Sistemas de Informação, Matemática, Comunicação Social e Letras se uniram para a construção de um jogo de tabuleiro que permita o aprendizado da programação. A partir desta equipe, foi possível alcançar os diferentes conhecimentos exigidos para a construção de um jogo que ensine a programação, sendo eles: conceitos da programação, exercícios matemáticos, design do jogo, construção dos personagens e, construção dos enunciados de forma atrativa para o público alvo desejado.

Para a construção do jogo, utilizou-se a metodologia de práticas colaborativas através de algumas técnicas de design. A primeira técnica aplicada foi a Collaborative Analysis of Requirements and Design (CARD) [Preece et al. 2005], na qual foram disponibilizados para os participantes materiais para que montassem o seu tabuleiro. Porém, a técnica foi aplicada de forma colaborativa, sendo que a medida em que um integrante colocava uma parte do tabuleiro, os demais opinavam e adicionavam as suas contribuições. Na Figura 4 pode-se observar a reunião com a aplicação da técnica CARD na qual os participantes estão trabalhando com o jogo produzido até o momento. Nessa primeira etapa, houve a participação de membros dos cursos de Ciência da Computação, Sistemas de Informação e Letras. Antes de iniciar a reunião e a aplicação da técnica, 
solicitou-se aos participantes que estudassem os jogos correlatos, afim de terem uma ideia para a construção do jogo em questão. A técnica CARD foi utilizada, pois é uma técnica para análise de tarefas para o desenho de fluxos de atividades em um sistema [Tudor et al. 1993]. Através dela é possível ter uma visão macroscópica das atividades necessárias e da sequência em que elas são realizadas [Tudor et al. 1993], [Preece et al. 2005].

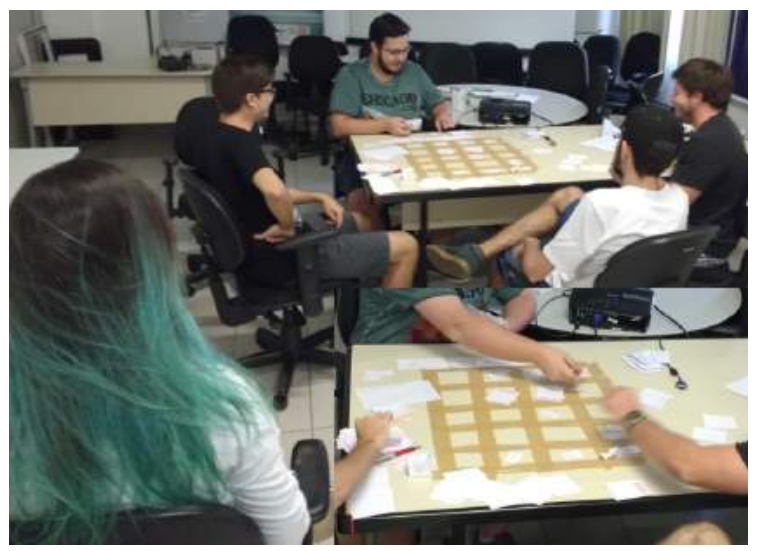

Figure 4. Reunião com aplicação da técnica CARD para construção do jogo

Com a técnica CARD foi possível identificar o fluxo do jogo, assim como as tarefas que devem ser implementadas para a sua conclusão. Durante a reunião, foram necessários alguns ajustes até se chegar à configuração do jogo, pois o CARD permitiu a visualização de problemas na dinâmica ou com as cartas. Após a conclusão da reunião, obteve-se a ideia do jogo, tendo como resultado as seguintes características:

- o jogo possui um tabuleiro formado por 12 linhas e 12 colunas;

- todos os participantes iniciam de uma mesma casa do tabuleiro, que é sorteada a partir de dados (assim a criança aprende conceitos básicos de matriz), sendo o 4 o número máximo de participantes;

- cada participante recebe 5 cartas, tendo uma direção (norte, sul, leste, oeste) ou um coringa (trocar cartas com o colega, trocar cartas com o monte, ficar uma vez sem jogar);

- o objetivo é chegar a um alvo no tabuleiro, que também é sorteado com os dados;

- para algumas rodadas, podem ser colocados obstáculos nas casa, também sorteados através dos dados;

- na sua jogada, o jogador pode escolher jogar as cartas (quantas quiser), afim de alcançar o objetivo ou trocar 2 cartas com o monte e passar a vez;

- vence o jogador que atingir o alvo por primeiro.

Após a definição do jogo, iniciou-se o processo do desenvolvimento do negócio, sendo neste caso o jogo. Para isso, as atividades foram distribuídas com a equipe interdisciplinar, sendo que cada um recebeu sua atividade e sua definição de fluxo. A Figura 5 apresenta um diagrama de atividades com a definição do processo colaborativo utilizado para o desenvolvimento do jogo.

Nesse processo, o time de computação ficou responsável pela definição do jogo, das regras e da validação do tabuleiro. O time da comunicação ficou responsável pela 


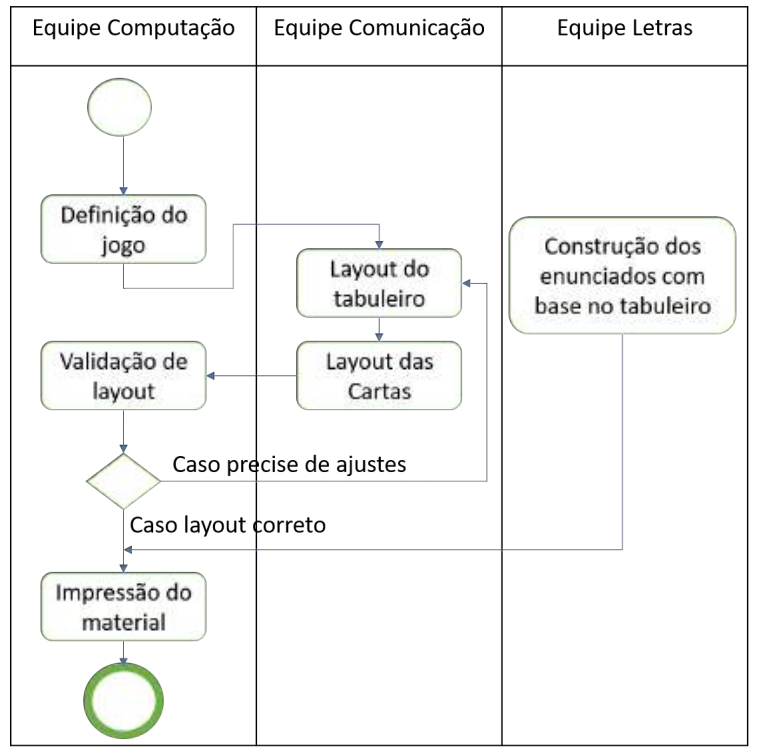

Figure 5. Processo colaborativo para desenvolvimento do jogo

aparência e desenho do tabuleiro e das cartas. Por sua vez, o time de letras se responsabilizou pela construção dos enunciados com base nas definições pré-estabelecidas pela reunião inicial.

A colaboração entre os membros da equipe é necessária para assumir a característica de um processo colaborativo. O objetivo de realizar a tarefa em conjunto é obter o feedback constante dos participantes de modo a evoluir a tarefa a ser concluída, além de identificar em conjunto as melhores estratégias a serem aplicada para a sua conclusão, de modo que uma tarefa se complete a outra. Sem estes elementos, não há colaboração e sim somente uma troca de ideias. Durante o processo de realização do jogo, essa prática foi constante e sistemática, reunindo a maior quantidade de membros da equipe. Sendo assim, apesar da divisão das tarefas entre as equipes, o trabalho para a realização de cada uma delas foi realizado de forma colaborativa entre os participantes daquela equipe. Por sua vez, após a conclusão de cada tarefa pela equipe, as equipes se uniam para discutir as melhorias possíveis na tarefa concluída, sendo outra colaboração fornecida no projeto.

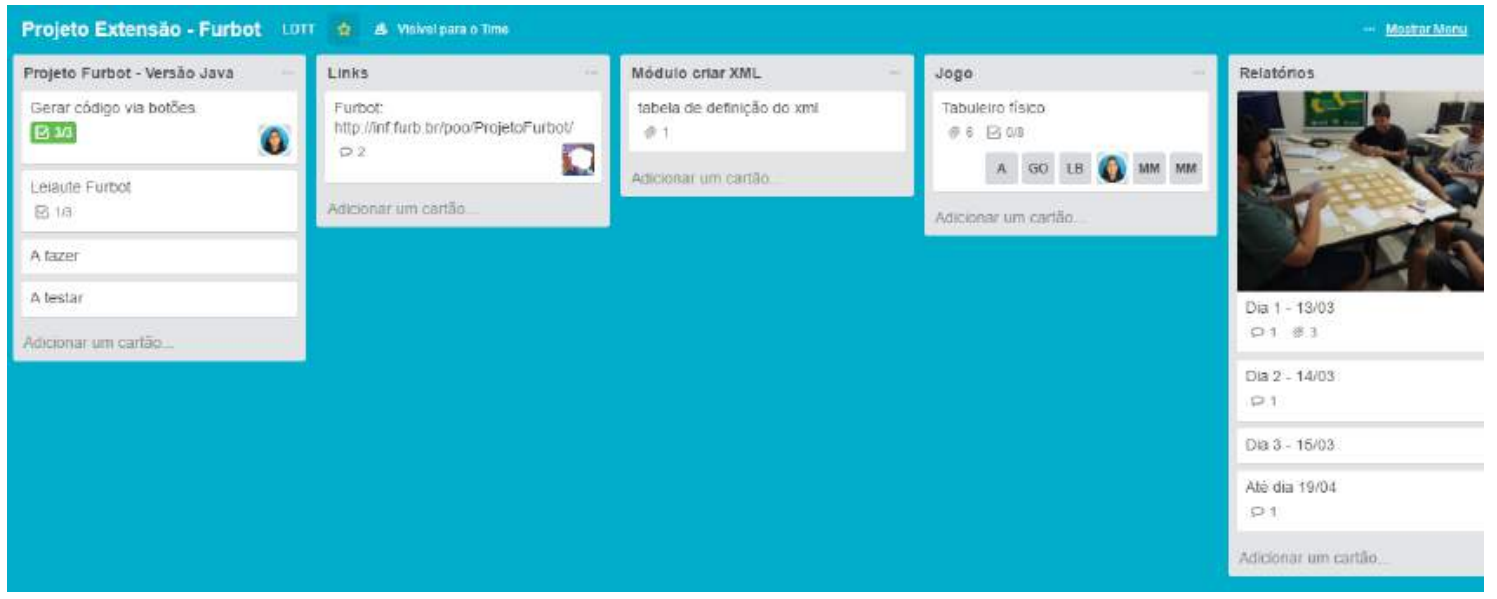

Figure 6. Método Kanban aplicado através do Trello 
Para a sistemática dessa colaboração, foram definidos métodos a serem aplicados no processo prático do projeto do jogo. O primeiro método, como já mencionado foi o CARD para identificação macro das funcionalidades do jogo e de como o mesmo seria jogado. O segundo, foi o Design Sketchboard, que segundo [Furnell 2010] é um método que se baseia em um esboço para desenvolver e compartilhar rapidamente conceitos de um projeto. Esse método foi utilizado para desenhar o tabuleiro de modo que a equipe de comunicação pudesse identificar como produzir o visual gráfico do tabuleiro, a equipe de computação pudesse iniciar a produção do desenvolvimento do jogo e a equipe de letras e matemática pudessem descrever as atividades. Para a concepção do tabuleiro, todos os membros se uniram aplicando esta técnica em folhas de papel até obter a definição do layout. Por fim, para que a comunicação se desse de forma colaborativa utilizou-se o Kanban por ser uma forma de colaboração contínua, incentivando o aprendizado e a melhoria do trabalho [Bernardo 2014]. O Kanban foi aplicado através da ferramenta Trello, como pode ser visualizado na Figura 6, pois alguns membros da equipe trabalhavam em horários diferenciados ou em outras localidades, sendo necessário uma ferramenta online para permitir que esta colaboração pudesse ser efetivada. Através do Trello foram criados cards por funcionalidades que foram compartilhados com todo o time de modo que cada um pudesse dar sua contribuição e seu feedback.

\begin{tabular}{|l|l|l|l|l|}
\hline & \multicolumn{1}{|c|}{ Comunicação } & \multicolumn{1}{|c|}{ Coordenação } & \multicolumn{1}{|c|}{ Cooperação } & \multicolumn{1}{|c|}{ Percepção } \\
\hline Planejado & $\begin{array}{l}\text { Trello como forma de } \\
\text { formalizar a comunicação. } \\
\text { Reuniões semanais com toda } \\
\text { a equipe. }\end{array}$ & $\begin{array}{l}\text { Cada equipe ficou com um } \\
\text { membro responsável por } \\
\text { gerir a tarefa em grupo }\end{array}$ & $\begin{array}{l}\text { Cada membro escolheu a atividade conforme } \\
\text { sua maior afinidade para ser seu trabalho } \\
\text { foco. Todos os participantes auxiliaram uns } \\
\text { aos outros nas tomadas de decisões para a } \\
\text { construção das funcionalidades. }\end{array}$ & $\begin{array}{l}\text { A escola que receberá o projeto ficou } \\
\text { interessada, pois acredita que o projeto } \\
\text { poderá auxiliar também no aprendizado de } \\
\text { outras disciplinas para os alunos. }\end{array}$ \\
\hline Perceptivo & $\begin{array}{l}\text { Cada membro teve acesso a } \\
\text { informação compartilhada e } \\
\text { conseguiu identificar o que } \\
\text { cada um dos demais estava } \\
\text { realizando no periodo }\end{array}$ & $\begin{array}{l}\text { O coordenador acompanhou } \\
\text { o processo via Trello e } \\
\text { pessoalmente durante cada } \\
\text { atividade. }\end{array}$ & $\begin{array}{l}\text { A equipe de letras levou seu conhecimento a } \\
\text { respeito de escrita textual para crianças, a } \\
\text { equipe de publicidade levou seu } \\
\text { conhecimento a respeito de layout, a equipe } \\
\text { de matemática levou seu conhecimento a } \\
\text { respeito de problemas e a equipe de } \\
\text { computaçãa seu conhecimento a respeito de } \\
\text { programação. }\end{array}$ & $\begin{array}{l}\text { Até o momento, a escola se mostrou } \\
\text { satisfeita com o trabalho desenvolvido. }\end{array}$ \\
\hline Reflexivo & $\begin{array}{l}\text { Ao final da execução das } \\
\text { etapas foi realizada uma } \\
\text { reunião para identificar o } \\
\text { resultado alcançado até o } \\
\text { momento e planejar uma } \\
\text { próxima etapa e intervenção }\end{array}$ & $\begin{array}{l}\text { Tarefa produzida conforme } \\
\text { esperado }\end{array}$ & $\begin{array}{l}\text { Todas as equipes passaram a ter um pouco } \\
\text { mais de entendimento sobre as áreas que } \\
\text { não eram de sua afinidade, pois para o } \\
\text { projeto ser executado, é importante o } \\
\text { conhecimento do todo }\end{array}$ & $\begin{array}{l}\text { A colaboração se mostrou ativa, pois foi } \\
\text { possivel desenvolver as atividades de forma } \\
\text { paralela e integrá-las sem a necessidade de } \\
\text { alteração de qualquer parte. Mostrando } \\
\text { assim, que as equipes e membros estavam se } \\
\text { comunicando e colaborando durante a } \\
\text { concepção do jogo. }\end{array}$ \\
\hline
\end{tabular}

Figure 7. Prática colaborativa na construção do jogo

Durante toda a construção do jogo, utilizou-se o modelo de prática colaborativa recomendado por [Santoro et al. 2012], como já foi apresentada na Figura 3, para estruturar o processo de colaboração. A Figura 7 apresenta a prática colaborativa para o processo de colaboração em cada uma das etapas do projeto. De modo geral, decidiu-se que a comunicação se daria através da plataforma Trello para que toda a equipe pudesse visualizar durante o desenvolvimento a troca de informações, além de ter uma percepção do andamento do projeto. Um membro de cada time ficou responsável pela coordenação do seu grupo de forma a realizar o acompanhamento das atividades. Durante toda a etapa, os membros das equipes cooperaram entre si, tanto para a definição, quanto produção e avaliação do jogo. Ao final, os membros se reuniram afim de validar o jogo produzido para então realizar a impressão do material.

O resultado do jogo pode ser visualizado na Figura 8. Decidiu-se construir um tabuleiro contendo o mapa de Blumenau e Santa Catarina, pois é um dos assuntos trabal- 

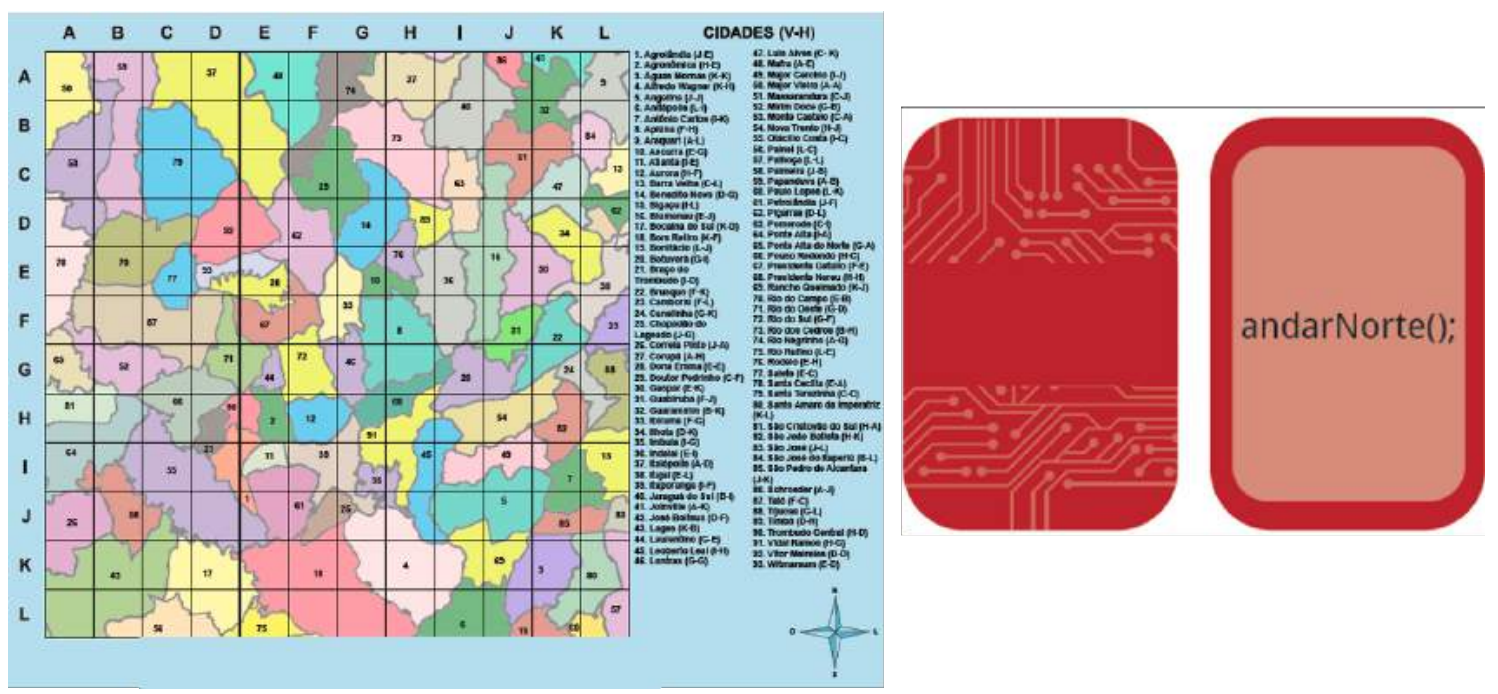

Figure 8. Jogo produzido pela equipe de forma colaborativa com um exemplo das cartas

hados com as crianças na escola. Assim, estarão num contexto conhecido, aprendendo uma prática nova. Sobre as cartas, optou-se pelo direcionamento conforme a rosa dos ventos disponibilizada também no mapa, dessa forma é mais um conceito de geografia reforçado durante a prática do jogo de programação.

\section{Conclusão e trabalhos futuros}

Baseado nos trabalhos correlatos, pode-se dizer que o jogo projetado tem semelhanças relacionadas aos três jogos. O tabuleiro resultante do jogo é semelhante ao jogo Robot Turtles [Lazowska and Etzioni 2014], pois é dividido em linhas e colunas, formando quadrantes para que o usuário atinja seu objetivo. Outra característica com este jogo é que podem haver obstáculos no caminho, fazendo com que o participante tenha que realizar um contorno pelo obstáculo. Com relação às cartas, tem-se a semelhança ao jogo Robot Wars [Akuthota 2016], pois as cartas disponibilizadas para os jogadores contém comandos que indicam a direção em que o jogador deve se mover pelo tabuleiro. Ainda, pode-se relacionar as cartas recursos com as cartas coringas, pois através delas o jogador deve tomar uma estratégia de quando utiliza-la afim de alcançar seu objetivo. Por fim, pode-se relacionar o trabalho em questão com o c-jump [Kholodov 2016], pois os comandos são executados de forma sequencial, podendo ser executados mais de um por vez.

Como experiência do trabalho interdisciplinar, a técnica do design de colaboração durante o processo do negócio foi positiva. A partir dela foi possível alinhar o time de modo que cada um realizasse seu papel para a produção do jogo ao mesmo tempo em que a colaboração foi fortalecida, devido as reuniões e os feedbacks constantes. Dessa forma, foi possível ter uma boa interação com a equipe e obteve-se um resultado conforme o esperado.

Como contribuição científica, este trabalho aplicou os métodos CARD, Design Sketchboard e Kanban no processo colaborativo da construção de um jogo. Todas essas técnicas se mostraram positivas, pois foi possíveis identificar as funcionalidades e o 
modelo do jogo antes de efetuar seu desenvolvimento, evitando um retrabalho. O método CARD foi utilizado para obtenção de uma visão macroscópica do jogo, o método Design Sketchboard para obter uma visão detalhada do tabuleiro e o Kanban para se ter um acompanhamento de forma colaborativo de todas as atividades do processo.

Como trabalhos futuros, será realizado um teste em campo com alunos de uma escola estadual entre 9 e 10 anos, afim de validar a construção do tabuleiro. Além disso, espera-se praticar o ensino da programação através do tabuleiro e de sua versão computadorizada, de modo que as crianças aprendam os princípios básicos para a programação de um sistema.

\section{References}

Akuthota, V. (2016). Robot wars board game: Introduce coding to kids. Disponível em: https://www.indiegogo.com/projects/robot-wars-board-game-introduce-codingto-kids.

Bernardo, K. (2014). Kanban: Do início ao fim. Disponível em: https://www.culturaagil.com.br/kanban-do-inicio-ao-fim/.

Fuks, H., Raposo, A. B., Gerosa, M. A., and de Lucena, C. J. P. (2002). O modelo de colaboração $3 c$ e a engenharia de groupware. Monografias em Ciência da Computação, no $=$ 17/02. Rio de Janeiro: PUC Rio.

Furnell, J. (2010). Facilitating collaborative design workshops: a step by step guide for rapidly creating a shared vision for execution. Disponível em: https://jasonfurnell.wordpress.com/2010/12/01/facilitating-collaborative-designworkshops-a-step-by-step-guide-for-rapidly-creating-a-shared-vision-for-execution/.

Kholodov, I. (2016). C-jump ski and snowboard race. Disponível em: http://www.cjump.com/.

Lazowska, E. and Etzioni, O. (2014). So, what is robot turtles? Disponível em: http://www.robotturtles.com/.

Pereira, C. S. and Soares, A. L. (2007). Improving the quality of collaboration requirements for information management through social networks analysis. In International Journal of Information Management, volume 27, pages 86-103.

Preece, J., Rogers, Y., and Sharp, H. (2005). Design de Interação. Bookman.

Santoro, F. M., Iendrike, H., and de Araujo, R. M. (2012). Capítulo 11 - colaboração em processos de negócio. In Pimentel, M. and Fuks, H., editors, Sistemas Colaborativos, pages 173 - 185. Elsevier Editora Ltda.

Tudor, L. G., Muller, M. J., Dayton, T., and Root, R. W. (1993). A participatory design technique for high-level task analysis, critique, and redesign: The card method. In $\mathrm{Hu}$ man Factors and Ergonomics Society Annual Meeting Proceedings, volume 37, pages 295-299. 